\title{
Thyroid Fine Needle Aspiration Biopsy Complicated with Massive Bilateral Hematoma Under Clopidogrel
}

Isabel Inácio ${ }^{1}$, Teresa Azevedo ${ }^{1}$, and Joana Guimarães ${ }^{1}$

${ }^{1}$ Centro Hospitalar do Baixo Vouga EPE

February 9, 2022

\begin{abstract}
Ultrasound-guided thyroid FNAB is a safe procedure even under antiplatelet drugs, such as clopidogrel. Although massive hematomas after FNAB are very rare, they may be fatal and must be promptly recognized and treated. Here, we present a well-resolved case of massive bilateral hematoma after ultrasound-guided FNAB using compression and ice.
\end{abstract}

\section{Hosted file}

Manuscript file.doc available at https://authorea.com/users/459589/articles/555812thyroid-fine-needle-aspiration-biopsy-complicated-with-massive-bilateral-hematoma-underclopidogrel
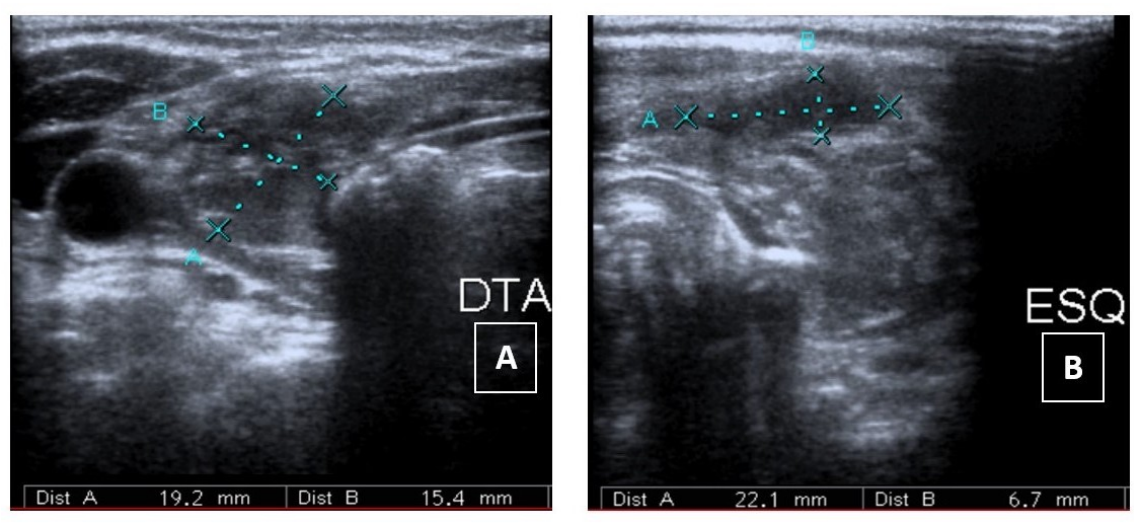